\title{
0 baldio como espaço de resgate afetivo
}

\author{
Maria José Carneiro Dias \\ Universidade do Porto - Instituto de Literatura Comparada
}

Resumo: A ficção de Maria Velho da Costa aposta na criação de territórios subjetivos onde, através de diferentes vozes enunciativas, se exibem cenários alternativos do mundo e se abrem espaços de indagação sobre a vida e o Homem. Pelo recurso a uma rarefação das coordenadas referenciais ou, como lhe chama Manuel Gusmão, a um «deslize da referência», através da montagem de cenografias que aludem ao mundo mais do que o representam, esta ficção abre espaços fronteiriços e intersticiais que permitem novos mapeamentos do humano. A estratégia de desrealização da realidade, libertando o texto de amarras factuais, cria o desprendimento necessário à criação de atmosferas de uma certa errância, de territórios baldios favoráveis à eclosão de figuras matizadas e recetivas a novos pactos relacionais e afetivos. É pela exploração das potencialidades de conceitos como liminaridade, vizinhança, interstício e latência que se perspetiva a sublimação da desafeição e se oferecem alternativas aos roteiros de devastação existencial. Ao encenar novas geografias do humano, em mundos plausíveis e porosos onde dialogam o imaginário e o psicótico, o real e o inverosímil, o humano e o animal, a ficção de Maria Velho da Costa oferece um exercício fecundante de mestiçagem em que se problematiza o que para a autora é fundamental: a realidade emocional dos afetos.

Palavras-chave: realismo, desrealização, cenografia, humano, baldio, devir

Abstract: The fictional works of Maria Velho da Costa generate multiple subjective territories where, by the
means of different enunciative voices, alternative world visions are displayed and new inquiring or
problematizing spaces are open, where life and the human are questioned. Through a rarefaction of the
referential coordinates or, as Manuel Gusmão calls it, through a «shift of the reference», by constructing
scenographies that mainly allude to the world instead of representing it, this fiction opens border and
interstitial spaces that suggest new human mappings. The strategy of toning down the reality, as it frees the
N. 038 - 6/ 2018 | 173-192 - ISSN 2183-2242 | http:/dX.doi.org/10.21747/21832242/litcomp38a10
INSTITUTO DE LITERATURA COMPARADA MARGARIDA LOSA | WWW.ILCML.COM
173 
text from its factual chains, creates the necessary detachment to allow the creation of atmospheres of a certain wandering, of no-man's lands suitable to the emergence of shading characters, receptive to new relational and affective pacts. By exploring the potentialities of concepts such as liminarility, neighbourhood, interstice and latency, conditions are created to put the sublimation of disaffection in perspective and to consider alternatives to the paths of existential devastation. As it figures new human geographies, in plausible and porous worlds where the imaginary and the psychotic, the real and the unlikely, the human and the animal interact, the fiction of Maria Velho da Costa offers a fecundating exercise of hybridity that deals with the author's fundamental topic: the emotional reality of the affection.

Keywords: realism; rarefaction of reality; scenography; human; no-man's-land; becoming

À distância ainda, numa clareira já brotada de trevo em campainhas amarelas e rosmaninho vivaz e tenaz, debaixo de uma azinheira que já não sabia a idade e frondosa, era um quadro de estranha paz e beleza.

Mais clichés, diz Rambo, impaciente, paciente. Eu fui feito pelos homens mas não fui feito para isto. Era já a premonição do ciúme. Que é dor de todas as espécies, mas especialmente do cão danado. Danado de donos e de dano.

Duas rolas, um par, arrulham na haste semiviva dum sobreiro que os encobre ainda da aparição debaixo da azinheira. Os céus estão estirados de cirros imóveis. É o bem, é o mal? (Myra: 89) ${ }^{1}$

O excerto acima foi retirado do romance Myra, de Maria Velho da Costa, e pretendese com ele fornecer o mote de uma abordagem aos territórios ficcionais da autora, frequentemente insituáveis e desrealizados. Nesta passagem, de sabor cénico, constrói-se um espaço de coloração fantástica que movimenta alusões a um imaginário cultural e religioso que remete, neste caso, para a canção "Grândola Vila Morena" e as aparições de Fátima. Neste cenário de margem de autoestrada surgirá Orlando, uma personagem mestiça, resplandecentemente vestida de branco e aureolada de magia, culta, rica e poliglota. Paralelamente, os comentários de Rambo, um cão Pitbull que acompanha Myra, uma adolescente imigrante de leste, alertam para a inverosimilhança do enquadramento 
ficcional. O reparo "Mais clichés" que se segue ao aviso “Olha a ilusão!”, umas linhas atrás, é estratégia desmistificadora e desrealizante, ou não o fosse já a existência no romance de um cão falante e opinativo.

Este é apenas um exemplo das cenografias que percorrem a obra ficcional de Maria Velho da Costa. De acordo com a formulação de Dominique Maingueneau, uma cenografia "define as condições de enunciador e co-enunciador, mas também o espaço (topografia) e o tempo (cronografia) a partir das quais se desenvolve a enunciação" (Maingueneau 1995: 123). Neste âmbito, trata-se da "inscrição legitimante de um texto estabilizado". Ora, o propósito de MVC orienta-se precisamente no sentido de fazer proliferar as inscrições, engendrando múltiplas cenografias e instabilizando o texto de forma a criar terrenos baldios, indemarcáveis e inclassificáveis, favoráveis à emergência de figuras matizadas e recetivas a novos pactos relacionais e afetivos. Trata-se aqui de engendrar pela ficção uma geografia feita de espaços incertos mas fecundos, passíveis de constituírem territórios mais humanizados, onde o ser humano possa ensaiar novas formas de ser e de estar, lidando de forma mais competente com os afetos.

Uma das estratégias desta ficção consiste na rarefação da referencialidade, aquilo a que Elisa, aspirante a escritora no romance Casas Pardas, abominará sob a designação de realismo retrateiro. Com efeito, os contextos desta ficção são os dum mundo desrealizado, de coordenadas espaciotemporais difusas e apenas aludidas, onde o conceito de ação narrativa se esbate na apresentação de fiapos de vida e onde cada personagem surge descentrada e desprendida de balizas factuais que de alguma forma a condicionem ou restrinjam às peias de um qualquer quotidiano. Esta estratégia, a que Manuel Gusmão chama um «deslize da referência» (Gusmão 1988: 51), consiste na rarefação da realidade palpável das coisas e na indefinição ou esbatimento dos espaços físicos, de forma a criar condições para a emergência da realidade íntima, afinal aquela que importa trabalhar nesta ficção, pelas possibilidades que se abrem de errância, de latência e de reconfiguração, numa espécie de ensaio de construção de um mundo novo para um novo Homem. A realidade apresenta-se, pois, em enquadramentos mais ou menos avulsos, numa espécie de instantâneos de vida, soltos e rarefeitos, onde as personagens nos aparecem em 
gestualidades quase sempre banais e sem alinhamento actancial. Surgem, assim, retalhos de vida que, embora abertos e difusos, vão escrevendo um texto do mundo onde se privilegia o espaço do íntimo e da subjetivação e onde, como diz uma personagem de Lúcialima, interessa "o corpo, a realidade, o corpo da realidade" (L: 103).

Não se trata aqui, porém, de criar personagens alheias ao mundo que as rodeia, pairando sobre um nenhures assético ou envolvidas numa nebulosa sociocultural e histórica impossível de identificar ou qualificar. Pelo contrário, nesta ficção, o sítio impregna a personagem condicionando a sua vida, ainda que sítio seja aqui usado num sentido mais lato, que abarca também uma geografia existencial constituída, por exemplo, pelo espaço da casa familiar, pela rede de relações sociais, ou até pelo espaço íntimo do eu consigo mesmo e do jogo de forças que aí se constrói. Myra, por exemplo, protagonista do romance homónimo, desconsiderada e espancada no seio de familiares com quem imigrou para Portugal, inicia um trajeto angustiado de regresso a um leste natal acolhedor, onde se sonha acarinhada pela avó. Este leste, designação propositadamente abrangente e esbatida, erige-se como miragem acalentada, geografia utópica onde Myra nunca mais regressará, e nessa condição configura um caso de uma topofilia construída na zona fluida entre a geografia física e a afetiva. Da mesma forma, quando Gabriel Orlando, em Irene ou o contrato social, constata as mudanças frequentes que a mãe opera na decoração da casa, uma mansão situada algures na região de Lisboa, é sempre a avaliação de um espaço afetivo que está em causa e que, em contra ciclo, se vai desinvestindo de calor afetivo e perdendo a natureza de espaço familiar de pertença, até ser apenas uma casa rica e decorada com gosto e requinte, mas à imagem da requintada insensibilidade da mãe. 0 mesmo acontece quando Elvira, personagem de Casas Pardas, decide mudar-se do quarto alugado, constrangedor da sua liberdade e intimidade, para o pátio alfacinha onde a sua vida encontrará harmonia e desabrochará finalmente em alegria e desanuviamento psíquico e emocional. Também Maina Mendes abomina o espaço da casa burguesa dos pais, e posteriormente a do marido, onde vê retraídos os seus gestos e a possibilidade de uma identidade, preferindo o espaço aberto da praia ou a cozinha onde impera Hortelinda, a cozinheira que lhe garante a compreensão, a autonomia da descoberta de si e o abrigo afetivo de que está necessitada. 
Trata-se, nestes exemplos, de espaços físicos que marcam vidas e mostram como uma geografia doméstica ou íntima pode constituir um patamar de reflexão sobre as relações humanas, os afetos e o processo de construção da identidade e do conhecimento pessoal, na linha do que reconhece Patrícia Garcia: "the house: a starting point for our relationship to the universe, the most intimate space. A site to freely develop imagination related closely to the intricate mechanisms of human memory and identity formation" (Garcia s/d: 18).

Em qualquer dos casos apresentados, há personagens que se debatem por não estarem no lugar certo da vida, e é nesse contexto que cabe, então, falar também de topofobia, no sentido de geografias humanas íngremes e abrasivas de que urge escapar, de espaços vividos que importa abandonar em favor de espaços desejados. Assim, a teoria geocrítica é aqui convocada numa perspetiva de cartografia existencial e não num sentido de lugares físicos geograficamente demarcados, daí que o «deslize da referência» se apresente como um conceito operativo muito importante nesta ficção e ajude à explicitação da noção de «baldio» enquanto geografia desrealizada, terra de ninguém ou, zona franca, com as potencialidades que lhe estão associadas e que mais à frente se tratarão.

O efeito desrealizante da ficção de Maria Velho da Costa é também conseguido através do pendor dramático da sua escrita. Seduzida pelo cénico, esta ficção é uma arte da construção, um laboratório de simulações onde se fabricam e recortam figuras e cenários a partir dos quais emergem vozes e mundos. Nestes romances, tudo acontece "comme au théâtre", e as personagens adotam poses cénicas e assumem-se como máscaras ou títeres que estão sempre em cena, se camaleoam, dizem ser pastiches de outras ou estarem em exercício de se alienarem em diferentes versões de si mesmas, como Sara, de Missa in albis, que se identifica como aquela que "muda de nomes" (MA:15). 0 efeito cénico provocado pela linguagem, pelas referências à incidência da luz ou à movimentação estudada das personagens constrói episódios e lugares como que suspensos, cortados de qualquer enquadramento físico, numa lógica de desobjetivação do espaço que rarefaz os contextos para melhor fazer sobressair a voz que diz e torna presente a figura. Por isso, os espaços desta ficção são os de uma "Casa Grande" algures no Alentejo, de uma "paisagem 
incongruente", de uma mansão edénica ou de um lugar indefinido na margem de uma estrada, que se hesita em classificar: "Era uma taberna, um bar, um café paupérrimo” (M: $60)$.

Invoca-se para estes espaços a condição de simulacro, de um possível multifacetado aberto à reconfiguração pelo leitor, num jogo de manipulação de dados possíveis que é assumido pelo autor, que sabe estarem em jogo, o que Vera Terekhov chama "la modalité du possible et celle de la volonté" (Terekhov 2003: 13). Se, como defende Thomas Pavel, a verdade ficcional é uma verdade modal, do possível (apud Terekhov 2003: 12), a ficção de MVC cria um interessante jogo em que se assume trabalhar sempre com os critérios da ilusão, desrealizando as referências, mas em que as personagens narradoras veementemente reivindicam, em exercício autorreferencial e metaliterário, o certificado de verdade do que narram, pois, como se diz em Missa in albis, o contado torna-se verdade e realidade pelo ato de narrar. Se, para Umberto Eco, a literatura "est une machine à produire des mondes possibles" (apud Terekhov 2003: 16) e se, como afirma Terekhov, "chaque fiction est une version actualisée parmi les actualisables" (idem: 12), para Maria Velho da Costa, a literatura produz mundos reais e cada romance constitui um conjunto de fiapos duma vida que se fez realidade no texto, pelo simples ato de narrar. Na verdade, como esclarece Vera Terekhov,

(...) les mots reflètent moins qu'ils n'inventent le monde. Il s'agit d'une véritable stratégie discursive qui repose sur l'art de l'illusion, où le possible est associé au vouloir. Le joueur, comme l'auteur, développe la vision qu'il choisit parmi d'autres mondes possibles, variantes du réel. Les mondes fictionnels ne redoublent pas mais enrichissent la réalité. Dans cette optique, le monde réel ne semble être qu'expérience parcellaire dans l'infinité des mondes possibles. (idem: 16)

Neste âmbito, o caráter como que provisório e esbatido dos lugares físicos criados pela ficção de Maria Velho da Costa, sem nunca cortar o contacto com a realidade, constrói mundos possíveis e abertos, aproximando-se da noção de "terceiro espaço" defendida por Homi Bhabha (1990:211), no sentido em que aqui se aponta para uma indefinição ou hibridismo que obedece a uma lógica de potenciação do espaço enquanto abertura, 
mobilidade e porosidade, rejeitando ancoragens e criando condições para se engendrarem fenómenos de reterritorialização ou de reconfiguração. Na verdade, o aparato desrealizado da ficção de Maria Velho da Costa nunca se demite de dizer o mundo. Jogando a sua dupla condição de mundo do texto e de texto do mundo, os romances de MVC são exemplos de um realismo do íntimo, onde, escapando ao individualismo e ao psicologismo, o humano se exprime através da instauração no texto de múltiplos territórios subjetivos, onde cada figura se diz, num fluxo de consciência profundamente revelador do humano e dos seus desacertos afetivos. Este processo instaura-se sobretudo ao nível da variação e da baralhação da enunciação, mas também ao nível da tipologia dessa enunciação.

Seduzida pela prática do desvio e da dissonância, que cultiva como uma estratégia pessoal de sobrevivência mutante e de abertura a outras formas de ver, a autora vai cruzando e fazendo dialogar várias linguagens, rasgando espaços subjetivos alternativos, potenciadores de uma indagação sobre a vida, o Homem e o que para a autora é fundamental: a realidade emocional dos afetos. Trata-se nesta ficção de investir em espaços de subjetivação, de fazer do texto interface de relações múltiplas, o que, numa poética da voz como é o caso da escrita de MVC, subentende criação, disseminação e cruzamento de diferentes vozes enunciativas que dizem e problematizam o mundo. Esta voz, ora se copia laboriosamente a partir de uma fonte íntima que fala, ora se constrói e se contorciona a gosto, ora irrompe caótica a partir de um alhures íntimo e se impõe autonomamente no texto, em compulsão de registo, ora se deixa direcionar pela mão que escreve e molda o discurso, ora é captada em errância pelo ouvido atento da entidade escrevente, ora se ouve dentro de si em circunspecta escuta e auscultação refletida, e se procura e se escava em exercício de decifração profunda, ora se convoca através de múltiplas estratégias de transtextualidade.

A vocação rapsódica e polifónica desta escrita produz, assim, territórios de uma intensa subjetivação, construídos pelo fluxo de consciência das personagens ou de vozes, às vezes insituáveis, que deflagram no texto e o vão materializando num jogo enunciativo interno ao próprio texto, que ao dizer-se se vai corporizando em gente e vai produzindo fiapos de discurso como estes: "Quem fala? De que fios?"; "Nem saberás que tu profiro, se o 
de ti ou esse outro."; “E esta gente, quem sois?”; “Ó vozes que entrais..."; "Que vozes, a que passos recusar acesso a este quarto?"; "Não deixes proliferar as tuas vozes, não deixes..."; "Não sabes quem comanda esses gestos."; "Vozes, vozes..."; “Como me perco..."; "Nothing matters but the quality of the affection..."; "Un jour, Elsa, mes rêves monteront à des lèvres...". Também aqui conviria invocar a noção de terceiro espaço, no sentido da remissão para atmosferas híbridas e polifónicas, multifocais e oscilantes, numa lógica de estilhaçar o facilmente mapeável. Com efeito, as vozes que irrompem, sendo insituáveis, desinstalam o leitor e erigem-se em agentes de passagem para outro sítio, em facilitadores de travessia para uma espécie de zona franca, de trânsito relacional mais intenso e mais abrangente.

Da mesma forma, o gosto poliglota, que a autora designa sob a expressão crioulo galáctico (CP: 342), bem como o fulgor citacional, que a leva a criar o que ela própria chama um "mistério glososo" (ICS: 157-158), abrem na sua ficção um "além-texto" em que vozes outras rasgam novos corredores semânticos e convidam a diálogos pluridimensionais, abolindo fronteiras entre artes, géneros, tempos e línguas. Alguns excertos constituem uma apoteose da transtextualidade, tal como a concebe Genette (1982: 7). Veja-se como se opera esta encenação de pluralidade nos romances Irene ou o contrato social e Myra:

"Todos conhecemos gente inteligente que reza, mas não rezam ao Pai. Rezam a ela e só a ela por prémio pretendida." - Luís de Camões - (ICS: 14); "Hamlet sem fantasmas com a mãe afinal enfim feliz, feliz, feliz. E irmãos moiros, meio loiros. Como a Vânia-Vanessa que punha e dispunha do pobre mito. O woman thy name is not frailty." - Shakespeare - (ICS: 49); "Raquel põe o CD da Callas mais alto. Nunca tinha ouvido que o mesmo são a música e as palavras. No amor, ninguém fala sozinho e até os mortos vão ao nosso lado.

Croce e delizia. $O$ sink hernieder Nacht der Liebe my fair lady Meu amor não tenhas pressa longi di bo ke mi tem sufrido Croce e delizia al cor Si tu meurs et tu vas loin de moi Misterioso altero." Nesta sequência, cruzaram-se Lopes Graça, La Traviatta, de Verdi, Tristão e Isolda, de Wagner, o filme My Fair Lady de Geoge Cukor, o Fado "Vianinha”, de Mariza, a morna "Lua Nha”, cantada por Cesária Évora, e Edith Piaf em "Hymne à l'amour", (ICS: 169);

Camões, que é uma das afinidades eletivas de Maria Velho da Costa, surge com regularidade no seu texto. Veja-se uma outra ocorrência: 
Ouve, diz o velho cego, é a tua paga.

Eu vivi no mundo muitos anos e cansados. Corri terras, e mares apartados, buscando à vida algum remédio. Soneto Cem, pensou Myra, do único livro que trazia na mochila. Mas nada disse, pasmada. (M: 80)

Numa poética de auctoria e de dramaticidade enunciativa, como é a de Maria Velho da Costa, a estratégia de atravessamento textual a que se assiste nos seus romances opera um deslocamento que não é só ao nível da referência mas também de um endosse subjetivo e autoral que entretece irmandades dialogantes, abre no texto novas espacialidades semânticas e ajuda a um falatório literário fecundante de sentidos. A transtextualidade que se opera nesta ficção abre e expande novos territórios semânticos e transforma o texto num entreposto literário e linguístico que nomadiza as leituras interpretativas e, através da instabilidade instaurada, imprime ao texto cosmopolitismo e transgressividade, porquanto o espaço do texto se torna convite à mobilidade, ao cruzamento e ao diálogo entre línguas e manifestações artísticas. O lugar da escrita literária engendra, a partir de outras artes ou outros textos literários, um espaço multifocal onde, como diz Edward Soja,

(...) everything comes together... subjectivity and objectivity, the abstract and the concrete, the real and the imagined, the knowable and the unimaginable, the repetitive and the differential, structure and agency, mind and body, consciousness and the unconscious, the disciplined and the transdisciplinary, everyday life and unending history. (Soja 1996: 56)

Igual efeito descentrador provoca a convocação do discurso psicótico nesta ficção. De facto, o recurso à linguagem do inconsciente, do psicopatológico ou do temporariamente alienado por efeito das drogas ou do álcool, faz surgir no texto uma outra ordem, um outro espaço subjetivo que direciona o leitor para novas latitudes semânticas, zonas periféricas e desracionalizadas que o confrontam com outras facetas do humano. No caso em apreço, que é o de uma poética centrada na voz, o recurso a estas linguagens representa uma mais-valia pelas possibilidades expressivas que permite, rasgando caminhos de acesso ao que Maria Velho da Costa chama o "hortus inclusus", ou seja, o lugar da realidade íntima, alienada ou psicótica, frequentemente silenciada e escondida, lugar onde um eu se destitui da 
consciência de um dizer-se próprio através do qual ele se poderia fazer gente. Alienado de si, o eu fica remetido a um derrame de fala sem escuta, onde a loucura cresce. Veja-se como a dor se extravasa em Mariana Amélia, internada num hospital psiquiátrico:

“Doidas, doidas?, diz Mariana Amélia, 'não falo sozinha, não, a voz cai no ar é porque não há escuta, é então a escuta que faz não ser doido? Então os que não escutam estão é sem a minha fala, sem a minha fala, estão sós de a minha fala não estar. E quando eu falo estão os que não estiveram.

(...) Se os pássaros têm cornos e os bois azulam, é porque ninguém vê. Deixar, deixar, uma cabeça tão cheia de outra voz que se não possa ouvir a si mesma. Põe, tira, rapa e torna, fica um buraco para todo o vento, a boca que se não pode escolher. (L: 260-261)

O discurso psicótico, as associações de sabor lacaniano e as transgressões, sendo de uma grande funcionalidade na produção do ludus verboso que apaixona a autora, mas que não cabe tratar aqui, constroem um outro tipo de território subjetivo de um cenário humano desregulado, mas nem por isso despojado de uma intensa humanidade ou alheio à necessidade de se considerarem e se refletirem outras coordenadas humanas por vezes esquecidas, de um lado tido como marginal, destituído, ou doente. Desde as pequenas mas significativas transgressões, que transformam pedófilos em poderófilos, nursery rhymes em histery rhymes ou andorinhas em retorninhas, porque regressam sempre, até ao discurso psicopatológico, a paleta é vasta e deixam-se aqui apenas alguns exemplos. 0 primeiro, de Lúcialima: “(...) Os olhos não estão parados e perfazem um circuito alarmado exactamente à volta da cabeça de Maria Isaura, como um pássaro num interior, que não fita, dementia praecox, surtos esquizoides sem remissão já, hospitalismo, nomes. Cai em nós, Maria Isaura" (L: 106). Um outro, de Maina Mendes: "Sei o que quer que afirme - Pequei contra minha filha. Sei o que estou afirmando minha filha é in-pecável. Não pecável contra, porque feita desfazendo o morto em torno" (MM: 212). Outro ainda, de Casas Pardas: “(..) pausa entre pausas hiato hiante aliterantemente aliteratado, ali tratado em (...)" (CP: 21). E, finalmente, uma citação de Missa in albis: "Rir-se-iam. Era tão frágil. Mimo a mão tão exaurida que já nem mima: pertinácia no inverosímil. Bóris II também censurava daquele ferino verde-aço. Assanhou-se última hora dela gatos não gastam desarmónicos sons, ralos” (MA: 445). 
O recurso ao inverosímil, quer na modalidade da utilização de figuras fantásticas, quer na modalidade da humanização do animal, constitui outra forma de abrir novas territorialidades literárias e, por conseguinte, diferentes dimensões enunciativas, que fornecem outros tantos territórios de indagação do humano e da sua forma de lidar com os afetos. O fantástico entra na ficção de MVC através de figuras como a fada Éukié, no romance Lúcialima, o anjo movido a side-car, no conto "Fátima", e a Dama na Mata, no conto do mesmo nome. A meio caminho entre o sobrenatural e o humano surgem ainda figuras como Ângelo, no romance Casas Pardas, ou Orlando, em Myra, personagem recuperada do romance Irene ou o contrato social, onde já era Ariel, um “Arcanjo, ou lá o que era...”, como diz a personagem Raquel, quando este lhe aparece, rodeado de insólito. Estas duas personagens, ambíguas e de contornos matizados, colocam-se, assim, numa zona fronteiriça e de latência, um terceiro espaço onde se adivinham possibilidades de construção de um novo humano e onde, deixando porosos os limites entre o humano e o fantástico ou o sobrenatural, se convida à consideração de outras dimensões, abrindo outras plataformas de interação humana e novos mapeamentos relacionais e afetivos. Constitui-se aqui, novamente, um mundo possível entre o humano e o não-humano engendrado no laboratório da ficção. Ângelo, aparecido no espaço do jardim zoológico de Lisboa, curiosamente talvez o único espaço físico exaustivamente descrito em toda a ficção de Maria Velho da Costa, oferece a Elisa o salto qualitativo que lhe permite aceder a um mundo harmonioso e dialogante, muito diferente da desafeição e da incompetência relacional que caracteriza a sua família. Por sua vez, Irene encontra em Orlando o parceiro da sua dor, que com ela contratualiza o acordo final de uma eutanásia salvífica e compassiva. Também Lucinha, a criança desamparada do romance Lúcialima, busca um espaço de desanuviamento. Afetada por uma cegueira psicossomática que lhe evita a visão de um terreno familiar conflituoso, a menina encontra um abrigo compensatório num território alternativo, fora das geografias fisicamente mapeáveis, numa zona intersticial de comunicação entre o humano e o fantástico, através do relacionamento com a fada Éukié, mas também com o animal, através da coelha Boloira.

Neste mundo ficcional devastado, onde impera a desesperança e a 
incomunicabilidade, onde o desamparo de Mary a leva a dizer "Nunca ninguém sofreu por causa de eu existir. 0 único cão que me lambia mais até morreu de sarna." (CP: 220-221), onde "Os melhores não sobrevivem." (MA: 447); "Ninguém se encontra" (L: 161) e "A vida é assim. Depravada." (ICS: 62), os animais oferecem-se também, desde cedo, como tentativas de sublimação do horror humano, situação para a qual o leitor vai sendo acordado através de propósitos como "Da realidade não prefiro a humana" (CP: 21), "nem todos somos humanos. Há bichos mais pessoais." (ICS:180-181), "os cães são melhores que gente" (M: 78), ou "Um dia destes hei-de ir ao Jardim Zoológico a ver se arranjo doutra maneira as minhas reminiscências e a família" (CP: 22). 0 jardim zoológico erige-se em Casas Pardas como geografia alternativa à casa de família, na cidade de Lisboa, constituindo um espaço outro, descentrado e acolhedor, como que sugerindo uma heterotopia de compensação, como a entende Foucault, quando, referindo-se ao espaços heterogéneos e irreais, ou utópicos, diz que a função destes "is to create a space that is other, another real space, as perfect, as meticulous, as well arranged as ours is messy, ill constructed, and jumbled" (apud Soja 1989: 17)

A relação intersubjetiva entre Myra e Rambo, o cão Pitbull, da mesma forma que a proximidade que se estabelece entre Irene e a cadela Maina, ou entre Lucinha e a coelha Boloira, traçam linhas de fuga alternativas à vivência dos afetos, investindo-se de uma função compensatória da aptidão afetiva que falta às pessoas. Construído numa zona intersticial entre o humano e o animal, o trânsito relacional entre Myra e Rambo, irmanados na consciência de um desamparo comum, corporiza um ser sendo, de que já falava Maria Gabriela Llansol a propósito da cadela Jade, e remete para o fenómeno do devir, preconizado por Deleuze e Guattari, esse território de simbiose rizomática onde nenhuma dimensão é definitiva e tudo se equaciona num "être-entre, passer entre, intermezzo" (Deleuze et Guattari 1980: 339). Veja-se como se corporiza textualmente esta simbiose: "Myra, sem se aproximar, deu-lhe o nome que ouvira chamar e começou a falar-lhe de manso, na sua língua materna" (M: 13; "Não penso, não choro. São toxinas que não preciso de exsudar assim. Sou cão." (M: 108); 
A ver se não caímos em cima de ninguém.

O cão, aterrado, disse,

Tem de ser?

Myra disse,

Tem de ser.

(..)

Rambo subiu, sentou-se. Percebeu que nada mais havia a perceber. Agarra-me bem, disse, para eu bater com a espinha antes de ti.

Myra tomou-o nos braços a atirou-se para trás, como um mergulhador equipado se atira de um barco de pesquisa submarina. Rambo ainda se debateu nos braços dela, na queda, mas eram já asas.

Foi o último pensamento vivo de Myra. (M: 221)

Estas formas de ser e de estar alternativas, integradas em mundos rarefeitos e porosos, revelam-se um conceito muito produtivo na ficção de Maria Velho da Costa. Constituindo lugares intersticiais e baldios, no sentido de não aprisionados a uma qualquer serventia nem cunhados por um qualquer título de propriedade, elas veiculam a ideia de vidas e naturezas humanas fluidas, híbridas e mutantes, abertas a um fazer humano que ensaia novas modalidades de ser. A aposta está, porém, ainda envolta de pessimismo e de uma certa aura sacrificial. De facto, Elisa nunca mais encontra Ângelo; no contacto com a fada, Lucinha ganha maior consciência da sua infelicidade; a criança visitada pelo anjo continuará estropiada e ofendida; o cliente da "Dama na Mata" entra numa rota de extermínio; Orlando, de Irene ou o contrato social, vem afinal morrer sem apelo em Myra, e esta, sempre acompanhada por Rambo, apenas tem o consolo de este lhe servir como companheiro de suicídio. Numa ficção onde importa sobretudo trabalhar a realidade emocional dos afetos, a manutenção desta disforia poderá apenas significar que o homem não está ainda disponível para essa metamorfose. Ou, como afirmam António e André Nóvoa, é necessário "Pensar para além das frequências do visível, do audível e do palpável. Conferir verticalidade ao espaço" porque "Ainda existem muitas terrae incognitae por explorar. Apenas não conseguimos vê-las ou não temos olhos que as alcancem" (Nóvoa \& Nóvoa 2015: 86)

Tratando-se de lugares não-geográficos ou de espaços sem referência toponímica

N. 38 - 6/ 2018| 173-192 - ISSN 2183-2242 | http:/dx.doi.org/10.21747/21832242/litcomp38a10 
explícita, como os aqui abrangidos sob a noção de baldio, Bertrand Westphal não os inclui no âmbito dos estudos geocríticos, tal como os concebia na obra La Géocritique: Réel, Fiction, Espace, escrita em 2007. Mais tarde, na introdução à obra Le Monde Plausible, o autor considera que "Affronter l'espace c'est donc aller à la reencontre d'une énigme, ailleurs, au-delà des limites du territoire maîtrisable" (Westphal 2011: 14), parecendo abrir um corredor de análise a mundos possíveis, construídos em espaços plausíveis, quando consideradas as circunstâncias de vida e os cenários existenciais da contemporaneidade. Com efeito, torna-se cada vez mais premente prestar atenção à paisagem geossocial e às cartografias existenciais e afetivas engendradas pelo quotidiano contemporâneo, marcadas por pessoas em permanente deslocação, ou em residência provisória, ou cada vez mais frequentemente desenraizadas e deixadas à sua sorte, gente sem abrigo físico, mas sobretudo desabrigada afetivamente e que tem vindo a fazer proliferar os terrenos baldios, os físicos e os existenciais. Se, como afirma Tally, "Situated always in the middle of things, as it were, geocritical theory maps the territories while projecting alternative visions, where new spaces are possible, even necessary" (2014a: 9), a noção de baldio permite espacializar o indefinível e o espaço possível, configurando desta forma um conceito operativo interessante no âmbito das novas territorialidades literárias e do que nelas germina como fomento e construção de alteridades. Neste âmbito, o baldio ajudará a considerar novos domínios na relação do homem com o mundo e, nessa sequência, poderá ajudar à análise de que fala Robert Tally em "The Timely Emergence of Geocriticism”, o prefácio à tradução que fez da obra La Géocritique: Réel, Fiction, Espace, de Bertrand Westphal: “Geocriticism allows us to emphasize the ways that literature interacts with the world, but also to explore how all ways of dealing with the world are somewhat literary" (Tally 2011: x).

No mundo líquido de que falava Zygmunt Bauman, e que a cada dia parece rarefazerse mais e ir vaporizando tudo o que há bem pouco tempo se podia designar como definitivo, a noção de espaço é cada vez mais difusa (veja-se a recente noção de espaços de co-working, o armazenamento de dados na nuvem, ....), acompanhando cenários do humano que parecem também eles ir perdendo espessura em relações fortuitas e inconsequentes, que vão formando uma resistência à afeição e esboçando roteiros futuros de solidão e 
desamparo. A própria noção de domicílio ou de morada tende a esvaziar-se pelo número crescente de pessoas em trânsito, seja por imperativos profissionais, por escolhas de vida nómadas ou por diásporas forçadas, como são as constantes levas de refugiados que vão cruzando o planeta. Hoje, a toponímia, o lugar fixo e mapeável, vai em muitos casos cedendo lugar ao baldio, à «no man's land», à errância, e, por isso, vão-se generalizando os fenómenos de travessia e de miscigenação a vários níveis. Importa pois, cada vez mais, analisar a teia de relações que se estabelece entre coordenadas temporais, espaciais e humanas, numa lógica de compreensão do que é hoje a condição humana e do que se vai perspetivando como um mundo em devir. Nesse âmbito, Robert Tally Jr. entende que a "Geocritical theory, with its emphasis on that spatiality which is itself also temporal and historical, seems well suited to addressing the cartographical anxiety of life «in the middest»" (2014a: 6).

No seu ensaio “Which way to inner space?” de 1962, James Graham Ballard avançava o conceito de psicogeografias, no que se oferecia já como uma abertura à consideração de uma espécie de mundo paralelo em que o ser humano se retrai sobre si mesmo e sobre o espaço físico da sua casa ou apartamento, e progressivamente vai fechando as portas ao mundo exterior, ao mesmo tempo que vai operando mentalmente a fusão de planos ou de mundos, criando um mundo seu, geograficamente circunscrito, à medida das suas projeções mentais. Interessado pelas questões do espaço, embora sobretudo ao nível da ficção científica, Ballard anuncia ainda assim novos mapeamentos do humano que se vão revelando cada vez mais próximos da realidade contemporânea e visam já a integração das novas realidades que vão surgindo e colocando novos desafios ao ser humano e às suas interações. Daí que este romancista considere que "the biggest developments of the immediate future will take place, not on the Moon or Mars, but on Earth, and it is inner space, not outer, that needs to be explored" (apud Garcia 2015: s/p).

Embora os contextos da ficção de Maria Velho da Costa sejam os de um mundo real, pesando embora algumas fugas ao universo do inverosímil e do fantástico, poder-se-ia aqui invocar em parte a noção de psicogeografia, despojando-a do que nela há de sugestão de universo intimista e ensimesmado, mas aplicando-a no sentido de uma nova cartografia 
existencial, de espaços de interação outros, de planos paralelos, nascidos das inquietações de indivíduos a braços com relacionamentos afetivos disfuncionais que querem ver resolvidos ou ultrapassados e que, não o podendo ser, buscam outras formas compensatórias (algumas delas engendradas na sua mente) do afeto que lhes falta. Num mundo onde se abrem a cada momento novos espaços virtuais de potencialidades infinitas, de realidades paralelas que a velocidade nos avanços tecnológicos faz prever mas não permite ainda configurar, é necessário estar aberto à mudança e evitar cristalizações, repensando padrões de comportamento e tipologias de interação do humano e maleabilizando as noções de proximidade ou distância entre mundos.

Nessa lógica, a noção de baldio, configurando um espaço sem dono, desaproveitado e maninho, oferece um enquadramento difuso que pode ser perspetivado simultaneamente como lugar geográfico ou existencial aberto, um "espaço em devir" e, nesse sentido, constitui uma zona de mobilidade permanente e de abertura à mestiçagem e à alternativa. 0 baldio oferece-se, assim, como agente poético de representação do espaço incerto e periférico, um não-lugar que a literatura investe de funcionalidade, tornando-o território fecundo no e pelo texto, e erigindo-o em cenário de possibilidades humanas, nomeadamente ao nível da resolução ou do desagravamento dos roteiros de devastação que muitos vão trilhando num quotidiano cada vez mais íngreme e afetivamente desabrigado. Como defendem António e André Nóvoa, "É impossível ter respostas definitivas para os problemas do nosso século. Mas isso não nos deve impedir de construir respostas provisórias que nos permitam abrir novas possibilidades de pensar e de agir. Mesmo quando os temas são difíceis, podemos sempre conversar sobre eles. De espaço" (Nóvoa \& Nóvoa 2015: 87).

\section{NOTA}

${ }^{1}$ As citações referentes às obras ficcionais de Maria Velho da Costa (MVC) apresentar-se-ão, no corpo do texto, pelas suas iniciais: MM- Maina Mendes; M- Myra; CP-Casas Pardas; MA- Missa in albis; ICS- Irene ou o contrato social; L- Lúcialima; D- Dores. 


\section{Bibliografia}

Bhabha, Homi (1990), "The Third Space - Interview with Homi Bhabha”, in Rutherford, J., Identity: Community, Culture, Difference, London: Lawrence and Wishart, 207 - 221

-- (1994), The location of culture, London and New York, Routledge.

Bachelard, Gaston (1957), La Poétique de l'Espace, Paris, Presses Universitaires de France,

$3^{e}$ édition, versão digital acessível em https://gastonbachelard.org/wp.../BACHELARDGaston-La-poetique-de-l-espace.pdf.

Bauman, Zygmunt, (2000) Liquid Modernity, Cambridge, Polity Press.

Costa, Maria Velho da (1969), Maina Mendes, Lisboa, Moraes Editores, (4⿳⺈⿴囗十一 edição, prefácio de Eduardo Lourenço, Lisboa, Dom Quixote, 2001).

-- (1973), Desescrita, Porto, Afrontamento.

-- (1976), Cravo, Lisboa, Moraes Editores (2ª edição: 1994, Lisboa, Publicações D. Quixote).

-- (1977), Casas Pardas, Lisboa, Moraes Editores (2ª edição: 1979, Lisboa, Moraes Editores; 4⿳⺈冂a edição: 1996, prefácio de Manuel Gusmão, Lisboa, Publicações Dom Quixote).

-- (1983), Lúcialima, Lisboa, Edições «O Jornal».

-- (1988), Missa in Albis, Lisboa, Publicações Dom Quixote.

-- (1994), Dores, Lisboa, Publicações Dom Quixote.

-- (2000), Irene ou o Contrato Social, Lisboa, Publicações Dom Quixote (2a edição: 2002, Lisboa, Publicações Dom Quixote).

-- (2002), O Amante do Crato, com um desenho de João Cutileiro, Porto, Edições Asa.

-- (2008), Myra, pinturas de Ilda David, Lisboa, Assírio e Alvim.

Deleuze, Gilles, Guattari Félix (1980), Mille Plateaux, Paris, Les Éditions de Minuit.

Dias, Maria José Carneiro (2014), Maria Velho da Costa - uma poética da au(c)toria, tese de 
doutoramento apresentada à Faculdade de Letras da Universidade do Porto no dia 4 de abril de 2014.

Doudet, Caroline «Géocritique : théorie, méthodologie, pratique», Acta fabula, vol. 9, n 5, maio 2008, URL: http://www.fabula.org/revue/document4136.php, consultada em 2 de maio de 2017.

Garcia, Patrícia (s/d), Geocriticism: an Emerging Field in Comparative Literature, doc. pdf acessível em www.academia.edu/.../Geocriticism_an_Emergency_Field_in_Comparative_ Literature.

-- (2015), “J. G. Ballard's One-Man Worlds”, in Reflexiones Marginales, no 28, ano 5, agosto/setembro, Universidad Nacional Autónoma de México, Facultad de Filosofía y Letras, documento digital acessível em http://reflexionesmarginales.com/3.0/j-gballards-one-man-worlds/\#_edn3.

Genette, Gérard (1982), Palimpsestes - La littérature au second degré, Paris, Éditions du Seuil.

Gusmão, Manuel (1988) “Textualização, polifonia e historicidade”, in Revista Vértice, no 6, II série, Lisboa, Editorial Caminho, pp.47-51.

Laurel, Maria Hermínia (2017), "Nota de abertura" à tradução de alguns capítulos de $L a$ Géocritique: Réel, fiction, espace, de Bertrand Westphal, Porto, Edições Afrontamento, Lda.

Llansol, Maria Gabriela (s/d), Amar um cão, (c/ ilustração de Ruth Rosengarten), Sintra, Colares Editora.

Maingueneau, Dominique (1995), O contexto da obra literária, São Paulo, Livraria Martins Fontes Editora Ltda.

Nóvoa \& Nóvoa (2015), "Três conversas de espaço", in Finisterra, L, 100, pp. 81-87, pdf. acessível em revistas.rcaap.pt/finisterra/article/view/7865.

Soja, Edward W. (1989), Postmodern Geographies - The Reassertion of Space in Critical 
Social Theory, London / New York, Verso.

-- (1996), Thirdspace: journeys to Los Angeles and other real-and-imagined places, Oxford, Blackwell Publishers.

Tally, Robert T. Jr (2011), "The Timely Emergence of Geocriticism”, translator's preface in Geocriticism: Real and Fictional Spaces, New York, Palgrave Macmillan.

-- (2014a), "Geocriticism in the Middle of Things: Place, Peripeteia, and the Prospects of Comparative Literature", in LEVY, Clément \& WESTPHAL Bertrand [dir.], Géocritique: États des lieux/Geocriticism: A Survey, Limoges, PULIM, pp.6-15.

-- (2014b) “U Views Until the Dragon Comes: Geocriticism and the Prospects of Comparative Literature", in Inquire: journal of comparative literature, Issue 3.2, February 2014 "Neither Here Nor There: The (Non-) Geographical Futures of Comparative Literature", documento acessível em http://inquire.streetmag.org/articles/125

Terekhov, Vera Gandelman (2003), Jeu d'échecs: littérature et mondes possibles, tese de doutoramento em Literatura Comparada apresentada à Faculdade de Letras, Línguas e Ciências Humanas de Limoges, em 18 de novembro de 2003, orientada por Bertrand Westphal. Documento acessível emtpgbesancon.com/bibli/pdf/virtuel/ GandelmanTerekhov_EchecsMondesPossibles.pdf

Westphal, Bertrand (2007), La Géocritique: Réel, fiction, espace, Paris, Les Éditions de Minuit.

-- (2011), Le Monde Plausible: Lieu, espace, carte, Paris, Les Éditions de Minuit. 
Maria José Carneiro Dias é professora na Escola Secundária de Paços de Ferreira, onde tem vindo a lecionar as disciplinas de Português e Literatura Portuguesa, e onde é também codinamizadora do grupo de teatro "Máscaras". Depois de um mestrado em Estudos Literários, Culturais e Interartes, em que abordou a ficção de Amin Maalouf enquanto estratégia de mediação simbólica entre Ocidente e Oriente, fez um doutoramento em Literatura Portuguesa com uma tese sobre Maria Velho da Costa e a sua poética de au(c)toria. É membro integrado do Instituto de Literatura Comparada Margarida Losa, onde tem desenvolvido trabalho no âmbito do grupo Inter e Transculturalidades. 